\title{
Teologías y teodiceas épicas. Estacio y la perspectiva ovidiana*
}

\author{
Cecilia Criado \\ Universidad de Santiago de Compostela \\ cecilia.criado@usc.es

\section{Epic theologies and theodicies. Statius and the Ovidian perspective}

\begin{abstract}
Desde hace ya unos años, la figura de Estacio está siendo objeto de una constante rehabilitación. Ello, sin embargo, no ha tenido como contrapartida una mejor comprensión del aparato divino de la Tebaida ni, concretamente, de las incoherencias (o indecisiones) en que Júpiter incurre a la hora de definir su relación con el fatum. Obviando el hecho de que el estatuto ontológico y teológico de Zeus-Júpiter es altamente inestable desde el momento fundacional del género épico, hay una tendencia clara a seguir apelando hoy día a la similitud que este padre de los dioses guarda con la Providencia estoica que, casi aporéticamente, semper paret, semel iussit (Sen., Dial. I 5.8.9). En el presente estudio, plantearemos como alternativa a esta perspectiva el estudio de ciertos pasajes de Ovidio y del Séneca pensador político, no teólogo. Veremos cómo el Júpiter estaciano guarda inopinadas similitudes con el ovidiano rector Olympi y con el senecano ciuitatis rector.
\end{abstract}

Palabras clave: fatum; Providencia; teología épica; Júpiter; Estacio; Ovidio; Lucano; Séneca.
Statius is receiving a much more positive approaches nowadays than years ago. They are really contributing to his recent rehabilitation. However, this new situation has not meant in practice a better understanding of the Thebaid's divine machine. More concretely, Jupiter's hesitations about his relationship with fatum are still considered narrative incoherences. Obviously enough, the ontological and theological status of Zeus-Jupiter was profoundly unstable throughout the whole of Greek and Roman literary tradition. Even so, classical scholarship still try to explain the Statian Jupiter in the light of the Stoic Providence that, almost aporeticly, semper paret, semel iussit (Sen., Dial. I 5.8.9). In this paper I shall bring up some Ovidian and Senecan passages, but I shall not appeal to the theologian Seneca, but to the political thinker. I hope to show that Thebaid' Jupiter bears strong resemblances to Ovidian rector Olympi and to Senecan ciuitatis rector.

Keywords: fatum; Providence; epic theology; Jupiter; Statius; Ovid; Lucan; Seneca.

* Este trabajo se inserta en el marco del GIFC de la USC (Grupo de Investigación de Filología Clásica de la Universidad de Santiago de Compostela) así como del Proyecto de Investigación Algunas dinámicas extratextuales de la producción literaria (008/PX204). Mi agradecimiento más sincero a las lúcidas sugerencias del Prof. Jesús Bartolomé (Universidad del País Vasco). 
Los tratamientos que de la casa tebana hicieron los poemas homéricos, la épica arcaica, la tragedia ática y el conjunto de la literatura romana no permiten establecer si la series malorum (Ou., Met. IV 564 y Stat., Theb. I 17) que atenaza la historia mítica de la estirpe de Cadmo se debe a la causalidad divina o a la humana. Tampoco en las ocasiones en que son aducidos la $\beta o v \lambda \eta ̀ ~ \Delta$ ió $\varsigma$ o el designio de Júpiter es posible llegar a una conclusión cierta sobre las relaciones que el padre de dioses y hombres guarda respecto a ese destino que aflige indefectiblemente a la familia sidonia. En realidad, podría decirse que el rasgo más significativo que tienen en común todas las documentaciones literarias de temática tebana es, precisamente, tanto el reconocimiento de la inextricable relación de Zeus-Júpiter con el destino como la también impenetrable relación de la divinidad con el ser humano. ¿Es posible que la presencia coercitiva del modelo homérico haya posibilitado que durante siglos la teología épica haya sufrido una tan escueta evolución? A ello parece apuntar el pesimismo que al respecto emana de las composiciones de Ovidio y Estacio, dos de los más conspicuos reescritores de la historia mítica de Tebas. Sus teodiceas son, en su pesimismo, homéricas. Parecería que la épica postaugustea se retrotrajese a los orígenes del género.

Conviene, en todo caso, matizar. En sentido estricto la teodicea de los autores de las Metamorfosis y de la Tebaida es iliádica pero en forma alguna odiseica. Precisamente en la Odisea se encuentra, por primera vez en la literatura occidental, la explicación del origen del mal en boca de un dios. Al menos desde la perspectiva de un lector moderno, su contenido es anacrónico pues anticipa, aunque en sentido lato, las conclusiones a las que llegará el racionalismo moral de la Grecia filosófica. A raíz de la muerte de Egisto a manos de Orestes, Zeus afirma que el hijo de Tiestes recibió su merecido por no escuchar las advertencias de los dioses de que no matase a Agamenón ni se desposase con Clitemnestra. Zeus hace preceder tales reflexiones de una explicación sobre el origen del mal que los hombres sufren (Od. I 32-34). Sus palabras suponen una drástica superación del pesimismo inherente al concepto del destino y del mal que permeaba la Ilíada ${ }^{1}$. El hado dictado por la divi-

${ }^{1}$ Cuya mejor expresión, como es sabido, se encuentra en Il. XXIV 525-533. En este

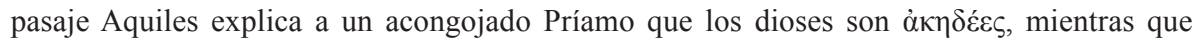
los hombres están condenados a sufrir. En efecto, continúa Aquiles, Zeus posee dos toneles que contienen, respectivamente, los bienes y los males. A unos hombres el dios les concede como don los bienes mezclados con males; a otros, en cambio, les reserva un lote enteramente luctuoso. 
nidad o por las otras fuerzas arcaicas del destino ya no tiene el poder de contemplar la totalidad. El hombre, afirma Zeus, posee una cierta capacidad de actuación y será este ejercicio de libertad lo que lo lleve a soportar pena-

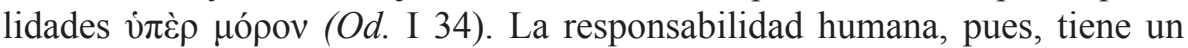
importante papel en la parte de mal que al hombre toca. Es sorprendente la proximidad de las palabras del Zeus homérico con el contenido del Himno a Zeus de Cleantes en cuyo verso 17 el filósofo afirma que todo procede del designio de Zeus, excepto las malas acciones que los hombres malvados

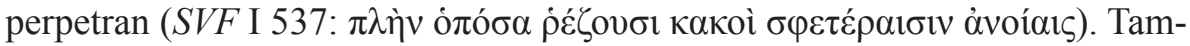
bién es obvia su cercanía con el fragmento que Calcidio, ya en fechas tardías, atribuyó a Cleantes. Según dicho testimonio, frente al punto de vista ortodoxo mantenido por Zenón y Crisipo, Cleantes habría defendido que el concepto de destino era más amplio que el de Providencia ya que, mientras todo lo que sucede por mandato de la Providencia también proviene del destino, hay cosas que provienen del destino pero no de la Providencia (SVF I 551 = II 933 = Chal., Comm. 144). Lógicamente, antes de dar fe a esta iconoclasta matización de Cleantes sobre la $\varepsilon i \mu \alpha \rho \mu \varepsilon ́ v \eta$, tendría que quedar establecida sin sombra de duda la autoridad de Calcidio sobre el temprano estoicismo. Y ésta, a lo que parece, está muy lejos de poder ser demostrada (Haase 1973, pp. 294-296). Pero lo cierto es que si, recurriendo a una legíti-

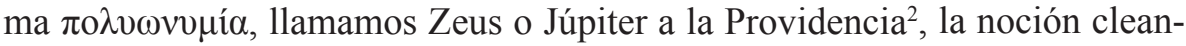
tea sobre la relación entre divinidad suprema y destino es la que, con la excepción de Hesíodo, parece primar en la épica desde los tiempos homéricos $\mathrm{y}$, de forma palmaria, en Ovidio y Estacio.

Todavía más llamativa es la seguridad que el Zeus homérico, obviamente prefilosófico, ostenta sobre una noción que se transformará en una de las cuestiones más arduas y aporéticas de los distintos sistemas filosóficos helenísticos: la problemática coexistencia de responsabilidad humana y libertad, por un lado, y destino fatal (o, en términos estoicos, determinismo causal

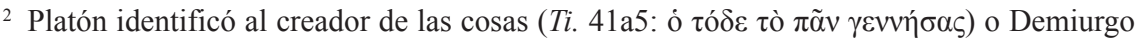

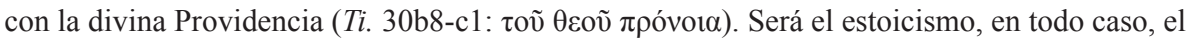
que confiera fuerza de ley a la $\pi$ o $v \omega \omega v v \mu i ́ \alpha$ aplicada a la divinidad suprema. De hecho, Clean-

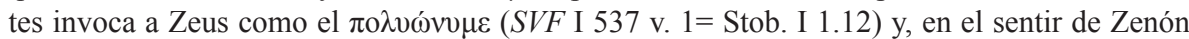
y Cleantes, es indiferente que se le llame Providencia, Zeus, Destino, Naturaleza o Razón $(S V F$ I $153=$ Cic., ND I 37; I $160=$ Lact., Inst. IV $9=$ Tert., Apol. XXI 10; I $176=$ Aecio 322.5-11); igualmente en Cleantes (SVF I $530=$ Cic., ND I 37.5-10; I $532=$ Minuc., Octav. 19) y en Séneca (QN II 45.1-2, Dial. XII 8.3-4 y Ep. IV 8.3 1-7). 
universal), por otro ${ }^{3}$. De hecho, habrá que esperar casi cuatro siglos para que un estoico, el esclavo Epicteto, haga la formulación más sistemática y depurada (Bobzien 1998, p. 388) del compatibilismo que posibilita cohonestar libre albedrío y determinismo (Arr., Epict. I 4). Ello no es óbice para que el

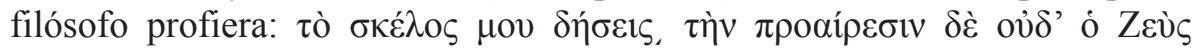

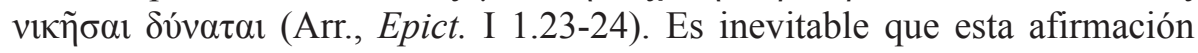
traiga a la mente la autoconsciencia poética del Ovidio de la sphragís de las Metamorfosis, convencido de que su opus no podrá ser destruido ni por la Iouis ira (Met. XV 870-871), en el bien entendido de que el Júpiter ovidiano es tanto el rey del Olimpo como su homólogo humano, Augusto ${ }^{4}$. En todo caso, ¿gozan los personajes ovidianos y estacianos de esa cuota de libertad que Zeus reconoce en la Odisea? En mi opinión, rotundamente no ${ }^{5}$. Júpiter lo confiesa en la asamblea del libro I de la Tebaida: mens cunctis imposta manet (I 227). Ni los personajes ovidianos ni los estacianos disfrutan del planteamiento teodiceico con el que Zeus en la Odisea superaba tanto la

${ }^{3}$ El mal como el resultado de la elección errónea de un ser libre lo encontramos ya en P1., Ti. 42a3-b2, así como las medidas que el Demiurgo toma para no convertirse en culpable de los males humanos (Ti. 42e3-4). Frente a las críticas epicúreas, Crisipo sostenía que el determinismo no negaba al hombre su carácter moral pues no destruía su libre albedrío. Comparaba la voluntad humana con el movimiento de un cilindro al que, tras serle imprimido un impulso externo, lo sigue en virtud de su propia naturaleza (SVF II 974 = Cic., Fat. 42.7-14, 43.9). Los esfuerzos estoicos por conciliar determinismo y libre albedrío no satisficieron, sin embargo, a Carnéades (Cic., Fat. 40). Séneca mismo se mostró renuente a enfrentar el problema. En Sobre la Providencia y en Cuestiones Naturales (II 32, 35), el hispano acepta en el sentido crisipiano el carácter necesario e inmutable del destino y nuestra sujeción a él (Dial. I 5.7.1: fata nos ducunt). Sin embargo, llegado el momento de abordar el punto crucial, esto es la conciliación teórica de fatum y libre albedrío, el filósofo romano se limita a posponer sine die una clara toma de postura al respeto ( $Q N$ II 38.3).

${ }^{4}$ Aunque la seguridad en la inmortalidad de la propia obra se había transformado en un lugar común en la poesía augustea (Verg., Aen. IX 446-449 y Hor., C. III 30), sólo Ovidio y Lucano (IX 980-986) osarán atribuir una cualidad demiúrgica a su creacción poética. Como creo que quedará claro a lo largo del presente artículo, en esta contestación a la teología épica canónica ha debido de tener más peso el posicionamiento ideológico de los poetas que el filosófico.

${ }^{5}$ No obstante, una importante parte de la investigación sobre Estacio defiende que la Tebaida enfatiza, igual que la Eneida, la libertad del hombre. De este modo, los estudiosos logran eximir a Júpiter/fatum de responsabilidad alguna en la maldad que exhalan los personajes del epos estaciano. Cf. Venini 1961b y 1964; Delarue 1990, pp. 1173 y 1176, y Taisne 1994, p. 60. 
relación dios (destino)-hombre como la noción del origen del mal que la Ilíada (XXIV 525-533) había establecido y que el mismísimo Eurípides, con gran efectismo intertextual ${ }^{6}$, ya había declarado obsoleta.

Durante décadas el aparato divino estaciano ha sido virulentamente criticado por su inoperancia e incongruencia. Claro está que hasta fechas muy recientes la Tebaida fue estudiada exclusivamente a la luz de Virgilio. La coerción de este virgilianocentrismo (sobre cuyos peligros recientemente alertaba Wheeler 2002, pp. 361-365) ha sido en gran medida la responsable de que el napolitano haya sido considerado un imitatore pedissequo del mantuano (Venini 1961a, p. 373). Hemos de admitir, sin embargo, que si la filología tradicional hubiese sometido a tan escudriñador y parcial análisis la figura del Júpiter virgiliano, se tendría que haber llegado a la conclusión de que sus contradicciones e irresoluciones pusieron seriamente en peligro el cumplimiento del plan glorioso de ese fatum que sancionaba la fundación de Roma $^{7}$. No es mi intención ahora contribuir a rehabilitar la figura de Estacio sino, meramente, constatar que su máquina divina adquiere significados inesperados si metemos en lid a Ovidio. Ciertamente, no cabe pensar que el autor de la Tebaida, uno de los poetas más conscientes de que la inspiración es una cuestión de intertextualidad (Rosati 2002, p. 231.), obvió a Ovidio en el grado en que parecía apuntar la falta de estudios específicos durante buena

${ }^{6}$ Cuando las mujeres argivas piden a Teseo que se apiade de su funesto destino, el ate-

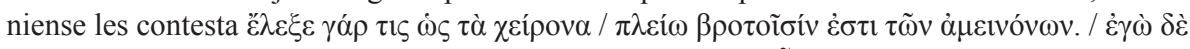

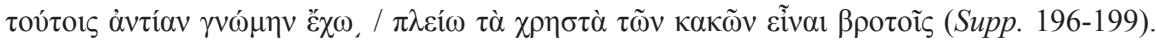

${ }^{7}$ A pesar de que en el libro I, cuando Júpiter desvela a Venus los secretos de los destinos, asegura que Eneas llevará a cabo una gran guerra en Italia (vv. 263-264), en el concilio divino del libro X, el Saturnio afirma que había prohibido que tal guerra tuviese lugar. Y lo hace con una expresión sancionada por la tradición épica, pues está en Ennio (cf. fr. 262 Skutsch: certare abnueo): abnueram bello Italiam concurrere Teucris. I quae contra uetitum discordia? (X 8-9). Juno se mostrará de acuerdo con su esposo cuando increpa a Venus, pues, aun admitiendo que la llegada de Eneas al Lacio se debió al destino (X 67), niega la responsabilidad de los fata en la guerra emprendida por el troyano (vv. 65-66). No obstante, no hay duda de que el padre de los dioses virgiliano sigue considerando que el enfrentamiento bélico era parte de su designio ya que, posteriormente, se declara dispuesto a conceder a Juno una demora en la muerte de Turno (X 622-624), pero se cuida de advertirle que es vana su esperanza de cambiar el curso de la guerra (vv. 625-627). Para las distintas explicaciones y justificaciones que se han dado a la coexistencia de «dos Júpiter tan distintos» (Thornton 1976, p. 123), cf. Heinze 1993 [or. 1903], p. 297, n. 43; Otis 1995 [or. 1964], p. 354 y Hardie 1998, p. 96. 
parte del siglo $\mathrm{XX}^{8}$. Naturalmente, por temática, Estacio tenía muy buenas razones para adscribirse con contundencia ya desde su proemio a la poética lucanea o senecana o, incluso, a la antimaquea (Carrara 1986, y Criado 1999a y 1999b). Ahora bien, los dos primeros versos de la Tebaida (fraternas acies alternaque regna profanis / decertata odiis), ven comprometida una filiación poética unilateralmente lucanea ${ }^{9}$, ya que el poeta afirma inmediatamente que va a soslayar, precisamente, aquellos pasajes de la historia cadmea que ya habían sido objeto de la atención pormenorizada de Ovidio. En efecto, la sección tebana de las Metamorfosis (II 836-IV 603) ${ }^{10}$ es un pasaje sin cuya presencia como hipotexto, las oscuridades del proemio de la Tebaida resultan, simplemente, ininteligibles (Delarue 2000, p. 200).

Indudablemente el concilio divino del libro I es «a magnificently Ovidian moment» (Feeney 1991, p. 353). Estacio, tras una dilatada presentación en la que amplifica la identificación ovidiana entre el Olimpo y el Palatino, reescribe su Júpiter a la luz de la atmósfera política contemporánea y lo presenta, también ovidianamente, como un autócrata. Pero no sólo. Tras la contundencia de los argumentos esgrimidos por W. Schubert 1984, es difícil hoy día no consentir en la malignidad cósmica del Júpiter de la Tebaida. En ella, de un modo muy trágico, ovidiano y lucaneo, el aparato divino (infernal y olímpico) es el principal motor de un mal ante el que el ser humano se encuentra impotente $^{11}$. Como es sabido, la idea de una divinidad que, más o menos inmotivadamente pero siempre de forma deliberada, arrostra la tarea de castigar o de destruir el género humano era nuclear en los prototipos sumerios y babilónicos de la inundación periódica. Así lo documentan tanto la tablilla de Nipur (ed. Poebel 1914, pp. 9-70) como los babilónicos Poema de Atra-

${ }^{8}$ Quedan ya lejos las aportaciones de Deipser 1881, Helm 1892, Mozley 1933 e, incluso, las de Thomas 1959, Aricò 1963, Kabsch 1968 y Newman 1975. Afortunadamente desde fechas más recientes, se han producido aportaciones esenciales. Véanse, por citar ejemplos sobresalientes, Colace 1982; Delarue 1988-1989 y 2000; Hardie 1988, 1990 y 2002; Iglesias Montiel 1991; Feeney 1991; Markus 1997 y 2003; Dominik 1994; Gildenhard y Zissos 2000; Keith 2002; Rosati 2002 y 2008; Newlands 2004, y McNellis 2007.

${ }^{9}$ Luc. I 4: cognatasque acies, et rupto foedere regni, 95: fraterno primi maduerunt sanguine muri y IV 554: cognato ... sanguine. Sobre la presencia de Lucano en el proemio de la Tebaida de Estacio sigue siendo imprescindible Kytzler 1960.

${ }^{10}$ Cf. Hardie 1990, p. 226, n. 13; Feeney 1991, p. 344, n. 10; Markus 1997, pp. 28-29, y Keith 2002, p. 382.

${ }^{11}$ Obviamente, hay todavía voces disidentes. Ramelli 1999, pp. 420-422, muestra su convencimiento en la benevolencia del Saturnio estaciano. 
hasis y Poema de Gilgamés. Sin embargo, el motivo de un plan divino para exterminar a la humanidad recibió en Grecia un desarrollo llamativamente marginal (Cypr., fr. 1 y Pl., Smp. 190b-e.). En realidad, los poemas homéricos y hesiódicos demuestran que, a pesar de la clara diferenciación entre los planos divino y humano establecidos por la religiosidad olímpica de la Grecia arcaica, la noción mesopotámica del hombre como siervo de los dioses debió de ser siempre extraña al pensamiento griego. Los dioses en la literatura griega podían ser benignos, siempre y cuando fuesen tratados adecuadamente, o, en el peor de los casos, distantes o indiferentes (Kirk 1992 [or. 1974], p. 220, y Detienne y Sissa 1990, p. 80), pero nunca sus ataques iban dirigidos a la destrucción de la humanidad. Y esta idea, con poquísimas excepciones, fue admitida de forma prácticamente unánime por la literatura y la producción filosófica romanas.

Pero analicemos estas excepciones. Dejando a un lado las dudas que se ciernen sobre las intenciones de Apolo en el fragmento de Lucilio ${ }^{12}$, es Ovidio el primer autor romano que introduce una divinidad, Júpiter, cuyo designio es la aniquilación del género humano. El medio del que se servirá será el diluvio universal. Sólo Licaón es culpable de haber cometido un acto blasfemo contra Júpiter; a pesar de ello, el padre de los dioses consigue el asentimiento de todo el panteón olímpico a su plan de que la humanidad perezca (Met. I 244-245). Posteriormente Séneca también recurrirá a la inundación y emulará a Ovidio en la descripción de su alcance apocalíptico ( $Q N$ III 27-30). Ahora bien, aunque comparte con Ovidio el énfasis en la fragilidad humana frente al poder de la divinidad, su planteamiento teológico es radicalmente distinto y de todo punto respetuoso con la finalidad correctiva que

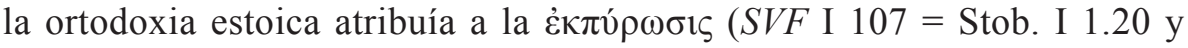
Eus., DE XV 18.3; SVF I 109 = Tat., Orat. 5; SVF I $510=$ Plu. 2.1075.D.3) ${ }^{13}$ así como con la «theocentric nature of Stoic physics» (Inwood 2005, p. 159).

12 Sat. I 53: serpere uti gangrena mala atque herpestica posset. No podemos asegurar que en este fragmento Apolo se dispusiese malévolamente a eliminar a los ciudadanos romanos bajo los efectos de una enfermedad. Ahora bien, la alusión a la maldad humana que Júpiter hace en las Metamorfosis en términos de inmedicabile corpus (I 190) puede ser argumento a favor de que la destrucción por enfermedad aparecía ya en el poeta satírico (cf. Romano 2009, p. 255).

13 En el mismo sentido SVF II 596-632. Cf. también Séneca en, por ejemplo, QN III 28.7.2-4: qua ratione? inquis. Eadem qua conflagratio futura est. Utrumque fit, cum deo uisum ordiri meliora, uetera finiri. 
Por tanto, antes de que Luciano, que conocía perfectamente la versión babilónica del diluvio, transformase en canónica la crueldad de Zeus (Icar. 29, 33), Estacio asumió claramente la problemática teodicea del Júpiter ovidiano. Rompiendo claramente con la tradición virgiliana, el designio de su padre de dioses y hombres es maligno ${ }^{14}$. Como ha sido señalado en numerosas ocasiones, su malignidad es a todas luces desproporcionada, pues lo que él se dispone a castigar no son los crímenes continuados de la tebana gens profana (Theb. I 232) sino reaccionar tardíamente a la imprecación que el anciano Edipo, afrentado por sus hijos Eteocles y Polinices, y consciente de la indiferencia de Júpiter, dirige a Tisífone al inicio de la composición. Para ello destruirá dos casas de las que él mismo se declara progenitor, la tebana y la argiva. La maldad de Júpiter es, entonces, teológicamente ovidiana y su afán punitivo no deja lugar alguno a la غ̇ $\pi \alpha v o ́ \rho \theta \omega \sigma ı \varsigma$ estoica a la que especiosamente el dios alude para justificar sus desmanes (Theb. VII 216-218: rogat hoc tellusque polusque / et pietas et laesa fides naturaque et ipsi / Eumenidum mores). La deuda del Júpiter estaciano respecto a la dicción ovidiana es evidente:

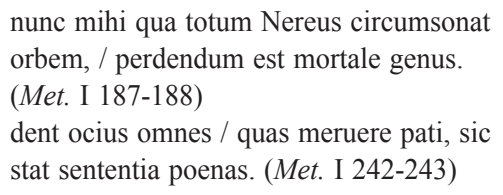

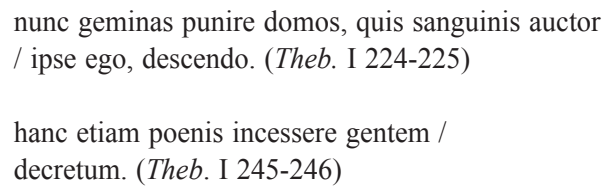

Según sus propias palabras, el dios se encuentra cansado de los terrarum delicta y del ingenium mortale (Theb. I 214-215) y, tras aducir como ejemplo de ello la arrogancia de Faetón (vv. 219-221), hace también una brevísima alusión al diluvio (vv. 222-223). Aunque no conviene restar importancia al hecho de que ya Horacio había aludido al motivo de la inundación ( $C$ I 2.120), llenándolo de inquietantes vinculaciones con las guerras civiles romanas, lo cierto es que tanto el episodio del hijo del Sol como el de Decaulión y Pirra habían sido tratados por Ovidio con dilación (Met. II 1-333 y I 262-312, respectivamente). Estamos, por tanto, ante una de las numerosas ocasiones en que el napolitano hace suya la técnica ovidiana de «expanding on a model's brevity and abbreviating a model's expansion» (Feneey 1991, p. 344 n. 106).

\footnotetext{
${ }^{14}$ A este respecto Kabsch 1968, p. 116, sugiere que Estacio quiere enfatizar metapoéticamente su deuda con las Metamorfosis para así destacar su contraste con Virgilio.
} 
Sin pretender agotar todos los hechos ovidianos que se encuentran en el inicio de Tebaida, permítaseme añadir que, antes de enumerar los crímenes actuales de la casa de Cadmo (esto es, el incesto de Edipo y la falta de pietas de sus hijos hacia éste), Júpiter hace un rápido recorrido por los primordia de Tebas:

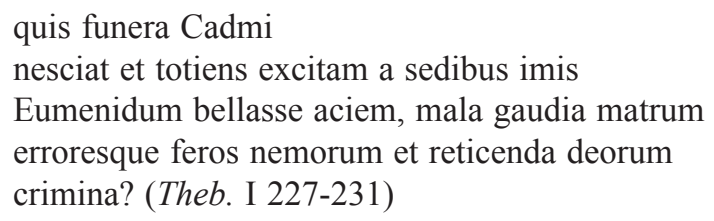

Estos versos, como los de la praeteritio proemial (I 4-16), constituyen un magnífico extracto del conjunto de la ya mencionada sección tebana de las Metamorfosis, que se situaba en el preciso parámetro cronológico de la arqueología de Tebas. Los momentos fundacionales de la estirpe cadmea, sin embargo, no van a ser objeto del canto de Estacio. Por sus importantes implicaciones teológicas, ha sido largamente debatida la cuestión de si el genitivo del infrecuente sintagma deorum crimina que Júpiter profiere en este pasaje (vv. 230-231) es objetivo o subjetivo ${ }^{15}$. En mi opinión, se trata de un genitivo subjetivo como subjetivos son los de Lucano (V 59: pudor crimenque deorum, VIII 55: crimenque deum crudele y VIII 800: crimine plena deum) en las ocasiones que recrea el caelestia crimina ovidiano (Met. VI 131). En todo caso, no es tan importante determinar este punto cuanto reconocer que Estacio busca la anfibología porque tal era la enseñanza de Ovidio. En las Metamorfosis, Aracne borda caelestia crimina, esto es, ocasiones en que los dioses, valiéndose de su poder omnímodo, ultrajaron a diosas y humanas. $\mathrm{Su}$ trabajo es contestación a la labor de Palas que previamente había bordado episodios que glorificaban a los dioses (VI 70-102). La propia persona narrativa reconoce que la obra de Aracne es superior a la de la diosa (vv. 129-130); aun así, es derrotada en la contienda «textil» y castigada por su jactancia. Poco antes se producía otra competición entre unas divinidades y unas mortales. Dicha escena se produce, precisamente, en uno de los momentos en que Tebas aparece de forma externa a la Tebaida ovidiana. El cadmeo monte Helicón aparece como el escenario adecuado para que la Tritonia

${ }^{15}$ Heuvel 1932, p. 148, Schubert 1984, p. 84, Feeney 1991, p. 355, y Schackleton Bailey 2003, vol. I, p. 57 n. 28. 
escuche por boca de las Musas el relato de la blasfemia de las Piéridas con ocasión del certamen poético establecido entre las diosas y las hijas del rey macedonio. A juicio de la Musa, éstas osaron entonar un canto que extenuat magnorum facta deorum (Met. V 320). De hecho, invierten el papel asignado por la tradición a los dioses en la Gigantomaquia, episodio que, junto a la Titanomaquia, la literatura había transformado en el símbolo canónico del incuestionable y legítimo poder alcanzado por Júpiter tras las luchas por la sucesión en el reino de los cielos. En justa contrapartida, cuando le toca el turno a la Musa Calíope, ésta asume el punto de vista pro-olímpico. Con la disculpa de narrar los avatares de Ceres en busca de su hija Proserpina (V 346-661), su canto se transforma en una contestación a la perspectiva humana de la divinidad que las Piéridas habían ofrecido. Para su rehabilitación del Olimpo, Calíope ofrece la lectura ortodoxa del mito de los Gigantes y de Tifoeo (V 346-358) e introduce el relato de la blasfemia del humano Ascábalo contra Proserpina (vv. 451-461).

Ambos pasajes ovidianos tienen una importancia radical para la comprensión de la evolución que la teología épica (no sólo en su aspecto teodiceico) sufrió en la épica postaugustea. En estos episodios, como en el resto de la composición, el de Sulmona «discute e fissa il superiore potere degli dèi nei confronti degli uomini» (Rosati 2001, p. 46). También Estacio (y, por supuesto, Lucano) presentará unos personajes que están siempre predestinados a enfrentar una lucha desigual contra un destino ineluctable y contra unos dioses arbitrarios y petulantes (Ten Kate 1955, p. 10 y Otis 1970 [or. 1966], pp. 128-164). Así, abandonando la participativa interferencia de plano divino y humano que encontramos en la Eneida, Ovidio y Estacio resultan retrotraerse al concepto arcaico de divinidad y asumen, en un sentido iliádico y esquileo, la absoluta contraposición entre la naturaleza y suerte de dioses y hombres; en definitiva, la radical separación entre el ser humano, condenado a morir y a sufrir, y los inmortales y beati dioses ${ }^{16}$. Pero, inesperadamente, al osar calificar moralmente el comportamiento divino, ambos autores adoptarán una perspectiva racionalista que, por supuesto, no es homérica pero tampoco esquilea. La insistencia ovidiana en este aspecto no tenía antecedentes en la épica romana; las raíces de tal pensamiento son, sin duda, trágicas, con-

${ }^{16}$ Sobre la distinción que la religiosidad de la Grecia arcaica establece entre los ámbitos divino y humano, véase Bianchi 1976, p. 59. 
cretamente euripideas ${ }^{17}$. En todo caso, Estacio, no encontrando satisfactorias las lecturas que los precedentes poetas épicos romanos hicieron del misticismo de los sistemas filosóficos helenísticos, parece abrazar, quizá inconfesadamente, la opción ovidiana (Criado 2000, p. 199). Así, el énfasis no omnipresente (Rosati 2001, pp. 41-42) pero absolutamente sistemático, según veremos, que Ovidio hace sobre el fatum y sobre la existencia de un poder superior al de Júpiter tiene una clara continuidad en el autor de la Tebaida, aunque ésta aparezca desdibujada por su fidelidad a múltiples modelos.

Respecto a este último punto, tal como Legras 1905, p. 185, notó, no cabe negar que el concilio del libro I de la Tebaida (vv. 197-311) tiene fuertes reminiscencias de la asamblea del libro X de la Eneida (vv. 1-117). No obstante, en lo que toca a la cuestión de las relaciones del Saturnio con el destino, los contenidos son opuestos. Mientras el Júpiter estaciano afirma su poder omnímodo sobre el fatum, el virgiliano comienza a replegarse respecto a la tajante seguridad que había mostrado en la conversación con Venus en el comienzo de la Eneida. En la asamblea de la Tebaida un autocrático Júpiter decretará, como en Ovidio, la destrucción pero, a diferencia de éste, Estacio atribuye al dios la condición de indiscutible fatorum conditor: graue et inmutabile sanctis / pondus adest uerbis, et uocem fata sequuntur (I 212-213). En el sintagma uocem fata (v. 213) se deja notar la presencia del mantuano pues Estacio reescribe el juego etimológico entre for y fatum al que Júpiter, todavía muy consciente de su omnipotencia sobre la existencia de hombres y dioses, recurría en su contestación a Venus en el libro primero de la Eneida: fabor enim, quando haec te cura remordet, / longius et uoluens fatorum arcana mouebo (I 261-262). En la Tebaida, vienen a continuación los ruegos de Juno para que su esposo no convierta a Argos en el blanco de sus iras. Las palabras con que Júpiter le contesta son coherentes con lo que, virgilianamente, afirmaba en el pasaje precedente, esto es en I 212-213: Stygia aequora fratris / obtestor, mansurum et non reuocabile uerbum / nihil fore quod dictis flectar (Theb. I 290-292). Y lo mismo sucede en Theb. I 302: certo reliqua ordine ducam. Pero aquí acaban las semejanzas con el Júpiter del primer libro de la Eneida pues, como es sabido, estos claros asertos se contradicen con el contenido de las dos únicas ocasiones en que el dios estaciano vuelve a hacer

${ }^{17}$ Los ejemplos se multiplican. Véanse, por citar algún ejemplo, E., Ba. 1348; Supp. 61012; IT 570-573; HF 343-347, 1307-1310, 1340-1346. 
mención de su relación con el destino. El padre de los dioses consuela a Marte por los males que sufre la casa tebana de la que este último es progenitor. Afirma ahora que los sucesos actuales se deben al dictado de los fata y las Parcas, y que permanecen fijados desde el principio de los tiempos. Sea o no epexegético el -que del v. 241, Júpiter admite su sujeción a estas figuras homéricas del destino: sic fata mihi nigraeque Sororum / iurauere colus: manet haec ab origine mundi / fixa dies bello (Theb. III 241-243).

De nuevo, corrobora su supeditación al fatum en la escena en que consuela al tebano Baco. El padre de los dioses declara que no es el resentimiento personal el que lo induce a sacrificar a los hijos de Edipo sino que immoto deducimur orbe Fatorum (Theb. VII 197). En estos dos últimos pasajes Júpiter, haciendo dejación del destino en manos de las Parcas, no lo dicta sino que se limita a asegurar su cumplimiento. Ni el propio Saturnio ni ninguna otra deidad pueden variar los designios del fatum. Quiero llamar la atención sobre la ocurrencia de deducimur. No es frecuente el verbo deduco en sintagmas en los que el destino es sujeto u objeto. La expresión habitual, muy frecuente en Séneca ${ }^{18}$, es ducere fatum o fata. Sin embargo, deducere es, junto con ducere, un término común en contextos de hilado o bordado (Mozley 1969 [or. 1928], p. 147, n. e.) y, a su vez, la labor de hilar está tradicionalmente relacionada con la trama del destino que las Parcas tejen. E1 estaciano immoto deducimur orbe Fatorum es, entonces, una metáfora de la labor de hilar, concretamente del hilado de las Parcas o Moiras. Orbe es, pues, el vellón de lana no cardada, no siendo necesario pensar en alusión alguna a la rueda de la fortuna. En el episodio de las hilanderas Aracne y Palas (Met. VI 36-145), a través del verbo deduco, Ovidio asociaba la acción de bordar o hilar a la labor poética (Rosati 1999, p. 250), tal como ya había hecho en el programático y proemial deducite carmen (I 4), iunctura que, como es sabido, remite al refinamiento estilístico de la preceptiva calimaquea $^{19}$. Ahora bien, a la luz del verso estaciano que nos ocupa, yo pienso que la intención de Ovidio es llegar más lejos: está declarando que él, en cuanto poeta, ostenta la labor demiúrgica que Estacio, precisamente, le usurpa a su Júpiter en los dos pasajes arriba mencionados. ¿Será que Estacio, también como poeta, quiere apropiarse de la potestad del hilandero destino?

\footnotetext{
18 Véanse también Cic., Diu. I 128.16; Luc. VII 601 y Stat., Theb. I 396.

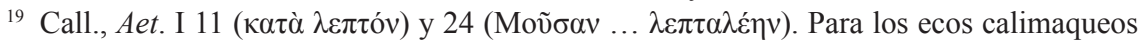
en el proemio ovidiano, cf. Wheeler 1999, pp. 8-30.
} 
A pesar de estas declaraciones de Júpiter en los libros III y VII de la Tebaida, existe práctica unanimidad respecto a que en la composición el padre de los dioses - con mayor o menor coherencia narrativa - gobierna sobre el destino, con el que mantiene una relación de interdependencia. Aceptar lo contrario implicaría admitir una inadmisible ruptura con toda la tradición poética anterior, tanto épica como trágica (Delarue 2000, p. 245). Yo creo, sin embargo, que son justamente los precedentes épicos y trágicos los que aconsejan no hacer una tan tajante afirmación ya que, con la excepción de Hesíodo, el estatuto teológico de Zeus-Júpiter es altamente inestable en toda la tradición literaria grecorromana. Según hemos visto, Júpiter confiesa en la asamblea del libro I de la Tebaida que mens cunctis imposta manet (I 227). La herencia genética posee, entonces, una fuerza coercitiva semejante a la que el Júpiter virgiliano confería a los fata en su réplica a Venus (Aen. I 257-258: manent immota tuorum / fata tibi) y similar también a la que padecen los personajes de Ovidio en los que, a pesar de la actividad transformadora de la divinidad, su natura anterior permanece inmutable. Un eco verbal cercano al verso estaciano se encuentra en Met. II 485: mens antiqua tamen facta quoque mansit in ursa, pero es un hecho que recurre a lo largo de las Metamorfosis ${ }^{20}$ y al que Ovidio parece haber conferido un valor teológicamente programático. A mi modo de ver, ello lo demuestra la insistencia que sobre este hecho el poeta hace al principio y al final de la composición.

En el libro I, Júpiter convierte la sangre de los sacrílegos Gigantes en figuras humanas. Su gestualidad correctiva, no obstante, cristaliza en un acto antropogénico bastante desafortunado pues también esta descendencia contemptrix superum saenaeque auidissima caedis / et uiolenta fuit: scires e sanguine natos (vv. 161-162). Poco después el padre de los dioses relata el castigo que infligió a Licaón por su blasfemia contra su divinidad y por su

${ }^{20}$ Veánse, por citar algunos ejemplos, el caso de Io que gemitu et lacrimis et luctisono mugitu / cum Ioue uisa queri finemque orare malorum (I 732-733), el de Acteón cuya mens tantum pristina mansit (III 203) y el de Cadmo y Harmonía que, tras la transformación, quidque prius fuerint, placidi meminere dracones (IV 603). El gesto cobarde de Fineo, su cara suplicante, sus manos sumisas y su actitud servil persisten tras su metamorfosis (V 234-235). En Galántide strenuitas antiqua manet (IX 320). Tampoco Midas cambió la tosquedad de su carácter (XI 148: pingue sed ingenium mansit, ... ut ante) y el amor y el pacto conyugal de Céix y Alcíone perduran una vez convertidos en pájaros (XI 743-744: tunc quoque mansit amor nec coniugiale solutum / foedus in alitibus). 
feritas. A pesar de que Ovidio presenta a Júpiter como la viva imagen del poder real incontestable (vv. 163-181), la voluntad vengadora (v. 230: uindice flamma) y punitiva del dios queda sin efecto pues, como él mismo reconoce, una vez transformado en lobo, todavía en Licaón conserva su avidez de matanza y las trazas de su antigua figura (Met. I 233-239). En el último libro - posición que ha de ser forzosamente significativa desde el punto de vista metaliterario - Pitágoras, explicando el eterno cambio, afirma que el alma permanece inmutable a pesar de que adopte diversas apariencias; se asemeja a la cera que nec manet ut fuerat nec formam seruat eandem, / sed tamen ipsa eadem est, animam sic semper eandem / esse (Met. XV 170-172).

Tampoco en la Tebaida el padre de los dioses tendrá poder alguno sobre la culpa hereditaria ${ }^{21}$. La herencia del crimen es un tema nuclear en la composición estaciana, pero ya era intensamente funcional en la épica ovidiana ${ }^{22}$, sobre todo en sus libros tebanos ${ }^{23}$, y sin duda hay que buscar sus raíces en la tragedia griega de tema cadmeo (Criado en prensa). Tanto en las Metamorfosis como en la Tebaida, el pecado de Cadmo permanecerá indeleble como transmisión genética en forma de predisposición al crimen, al error y a la arrogancia frente a los dioses que será heredada por sus descendientes. Pero si tal es el destino de los personajes ovidianos y estacianos, y Júpiter no puede hacer nada para cambiarlo, hay que consentir que la perspectiva adoptada es muy distinta a la creada por el optimismo teológico de la Grecia helenística que aceptaba la dependencia del fatum respecto a una divinidad personal, entendida por supuesto en sentido platónico, esto es como inteligencia moralmente positiva ${ }^{24}$. Pero incluso queda lejos de esa suerte de lata

${ }^{21}$ Heuvel 1932, pp. 144-145, aunque es un firme partidario de que Estacio se mantiene fiel en su composición al principio estoico de la identificación de Júpiter con el fatum, consiente que con mens cunctis imposta manet lo que el padre de los dioses estaciano quiere significar es que «originem meliorem quibusdam dare potui, mentem ne horum quidem uertere potui. Animus sceleratus, omnibus mortalibus insitus, corrigi nequit permanetque». Markus 1997, p. 85, afirma que en la Tebaida los dioses son tan víctimas y «helpless participants» de la guerra civil como los hombres.

${ }^{22}$ Met. VI 213, 458-460; VIII 485; IX 149-151, 123-124. Cf. Zeitlin 1986, p. 126; Hardie 1990, p. 225 , n. 12 , y Criado en prensa.

${ }^{23}$ Acteón (III 185), Sémele (III 293-295), Tiresias (III 333), Penteo (III 557-558, 701731), las Mineides (IV 1-4, 272-273, 390) y, finalmente, Ino (IV 420-421).

${ }^{24}$ Ya para Platón la característica esencial del Demiurgus era la benevolencia (Ti. 29a2, 29d7-30c1, 41a8-b2), igual que posteriormente lo será para el estoicismo (SVF I $548=\mathrm{Ph}$., Prou. II 74 = Eus. PE XV 15). Veánse también SVF II 1127-1131 y Cic., ND I 36. 
sinonimia e intercambiabilidad (bien es cierto que inconstante) entre la figura personal de Zeus y el destino (Magris 1985, p. 83) que es todo lo más que, en mi opinión, los poemas homéricos permiten deducir sobre la cuestión.

De forma pertinaz las contradicciones en que el Júpiter estaciano incurre han sido explicadas apelando a la formulación que Séneca hace de una de las más arduas antinomias estoicas que, presuntamente, encontrarían reflejo en los pasajes estacianos ${ }^{25}$ :

Quidquid est quod nos sic uiuere, sic mori iussit, eadem necessitate et deos alligat. Inreuocabilis humana pariter ac diuina cursus uehit: ille ipse omnium conditor et rector scripsit quidem fata, sed sequitur; semper paret, semel iussit (Sen., Dial. I 5.8).

En este pasaje, quizá significativamente, el filósofo corrige a Ovidio cuyo Júpiter, según veremos, no scripsit el destino sino que lo leyó (Met. XV 814). En todo caso, el recurso a la teorización senecana sigue siendo hoy día una tendencia constante en el caso de la épica flavia ${ }^{26} \mathrm{y}$ es, sin duda, una rémora de la tradición crítica de la Eneida que aún no ha sido abandonada ${ }^{27}$. Es cierto que Lucano hizo un bastante exacto trasvase del pasaje senecano a la dicción poética en II 7-1128. Ahora bien, en primer lugar, introduce esta

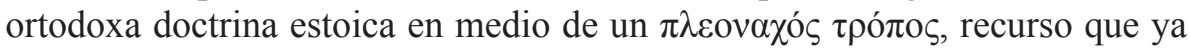
la tragedia y la épica grecorromana habían especializado para la expresión de la imposibilidad humana de comprender tanto los inescrutables designios del destino como el mal que, inmotivadamente, la divinidad envía sobre el hombre. En el ámbito de la literatura romana, Ovidio había institucionalizado la causalidad múltiple como la forma idónea para describir un mundo de incertezas en el que los dioses son poco fidedignos proveedores de la ueritas

${ }^{25}$ Legras 1905, p. 168; Heuvel 1932, p. 101; Vessey 1973, p. 83; Schetter 1960, p. 29; Thuile 1980, p. 222; Adamini 1981, p. 24, n. 10, y Delarue 2000, p. 295. Además del pasaje arriba citado, cf. también Sen., Ben. VI 23.1.1-2.1.

${ }^{26}$ Billerbeck 1986, p. 3129 y Groß 2003, p. 23. Mucho más cauto es Río Torres-Murciano 2006, p. 28. El altruismo inspirado por el humanismo estoico es la piedra de toque sobre la que Ripoll 1998, p. 312, fundamenta su análisis de la Pietas estaciana.

${ }^{27}$ Heinze 1993 [or. 1903], passim. Para el pasaje senecano que nos ocupa, cf. p. 237.

28 Siue parens rerum, cum primum informia regna / materiamque rudem flamma cedente recepit, / fixit in aeternum causas, qua cuncta coercet / se quoque lege tenens, et saecula iussa ferentem / fatorum inmoto diuisit limite mundum y, más brevemente en V 92-93: siue canit fatum seu, quod iubet ille canendo, / fit fatum. 
en asuntos éticos, políticos, físicos y teológicos (Schiesaro 2002, pp. 62-63 y 73$)^{29}$. Y en segundo lugar, inmediatamente después, Lucano no deja dudas de su dubitante estoicismo, pues vacila en atribuir la acción nefasta al designio estoico o a la no teológica aleatoriedad de los epicureos ${ }^{30}$.

Prescindamos, pues, de la filosofía. Realmente, ¿no es posible que, a pesar de nuestros esfuerzos por demostrar lo contrario, el conjunto de la épica posthesiódica haya sido, en cierta medida, literariamente incapaz de sustraerse al asistemático conglomerado teológico que caracterizaba la épica homérica? A ello parecen apuntar las «contradicciones» de los épicos postaugusteos, pero incluso las del propio Virgilio. En mi opinión, intentar explicar el comportamiento de un Zeus-Júpiter literario en términos filosóficos es prácticamente estéril; todavía más, si tenemos que vérnoslas con el género trágico o épico y, más si cabe, si los autores objeto de estudio son concretamente Ovidio, Séneca trágico, Lucano o Estacio. Además, aunque Séneca sacrifica la claridad de la exposición filosófica en aras del efectismo de su ingenium, con su afirmación de que el dios semper paret, semel iussit (Dial. I 5.8.9) está, simplemente, reelaborando la idea estoica de que el dios es Ley para el Cosmos pero también Ley para sí mismo. Dicha formulación ya se encuentra en Zenón (SVF I 162 = Schol in Luc. II 9) y quizá en el heracliteo kotvós $\lambda$ ó $\gamma$ oৎ del Himno a Zeus de Cleantes (SVF I 537 = Stob. I 1.12). De este modo, según ya hemos apuntado, el racionalismo estoico lograba superar el pesimismo inherente a la ambigüedad que emanaba del Zeus de la religiosidad olímpica predemocrática. El dios, o Ley natural, rige sin duda sobre un mundo moral y él mismo es no sólo moral, sino benevolente. Por ello ha de plegarse a la legalidad de la Fatorum series que él mismo ha establecido. Ello no implica que el dios tenga menos poder sino que, como le corresponde, salvaguarda la coherencia del Cosmos que ha fundado. La legalidad de la potestas de la divinidad es, en todo caso y tal como el propio Séneca afirma, absoluta $^{31}$. A mi modo de ver, poco tiene que ver esta moralización del panteón olímpico con la malignidad de la teodicea que Ovidio y Estacio plantean

${ }^{29}$ Cf. también Verg., Aen. X 109-110.

${ }^{30}$ Luc. II 12-13: siue nihil positum est, sed fors incerta uagatur / fertque refertque uices et habet mortalia casus. Cf. Feeney 1991, p. 281.

${ }^{31}$ Ben. VI 23.1-3: statuerunt - sc. los dioses-, quae non mutarent; itaque non possunt uideri facturi aliquid, quamuis nolint, quia, quidquid desinere non possunt, perseuerare uoluerunt, nec umquam primi consilii deos paenitet ... Sine dubio stare illis et desciscere in contrarium non licet, sed non ob aliud, quam quia uis sua illos in proposito tenet; nec inbe- 
y con las coincidencias de los decretos del Júpiter estaciano con los de las deidades infernales (Dominik 1994, pp. 1-33; Criado 2000, pp. 196-204, y McNellis 2007, pp. 9 y 26-27).

Tanto la tragedia griega como la senecana pero, sobre todo, la épica ovidiana y lucanea ${ }^{32}$ dan más cumplida explicación que las teorizaciones filosóficas sobre alguno de los aspectos de la idiosincrasia del Júpiter estaciano. Por razones de espacio, me centraré en Ovidio. Precisamente en una de las ocasiones en que Tebas aparece en las Metamorfosis de forma externa a la sección tebana, Temis hace una profecía en la que anuncia que los hijos de Calírroe y Alcmeón envejecerán para así poder vengar la muerte de su padre. Entre los habitantes del Olimpo se produce un verdadero intento de motín (Rosati 2001, pp. 52-53, y Galasso 2009, pp. 121 y 129), ya que todos ellos querrían modificar la edad de sus respectivos hijos humanos y así aliviar su vejez. Hay un fuerte contraste entre la autoridad con que Júpiter acalla la rebelión de los dioses (IX 428: o! nostri si qua est reuerentia) y sus palabras, que son una declaración — sin precedentes épicos — de su sumisión al fatum; la más trágica, honesta, clara y sistemática del conjunto de la literatura romana. Así, después de amonestar a los dioses, confiesa que también él está sometido al hado. Parecería que Ovidio anticipa el Zeus de Luciano ${ }^{33}$ y que se muestra inmune a la presión de los modelos literarios que, sin embargo, atenazarán al Júpiter estaciano:

uos etiam, quoque hoc animo meliore feratis,

me quoque fata regunt. quae si mutare ualerem,

nec nostrum seri curuarent Aeacon anni,

perpetuumque aeui florem Rhadamanthus haberet

cum Minoe meo, qui propter amara senectae

pondera despicitur, nec quo prius ordine regnat (Met. IX 433-438).

cillitate permanent, sed quia non libet ab optimis aberrare et sic ire decretum est. Cf. Leibniz 1900 [or. 1710], p. 387.

${ }^{32}$ El autor del Bellum ciuile sostiene la creencia estoica en el gobierno providencial del mundo natural (Schotes 1969, pp. 105-110 y 116-129); aun así, niega, la Providencia en relación con la humanidad (Criado 2000, p. 212) y nunca menciona el advenimiento de un nuevo ciclo tras la destrucción universal (cf. Narducci 1979, p. 37, y 2002, pp. 42-52 y 152-167).

${ }^{33}$ I. Conf. 3.8-4.4 y I. Tr. 18.3-5. 
La misma preeminencia del fatum (Parcas) sobre los designios de Júpiter se advierte en el pasaje en que el padre de los dioses disuade a Venus de su intento de salvar a César $^{34}$. Para Ovidio, Dios deja de ser una pregunta sin respuesta. Es muy significativo que en un poema que es la canción quintaesenciada de la mutatio constante e indefectible, lo único immobiles e immutabiles sean, precisamente, la herencia genética y el fatum. A todos los efectos, ello supone la práctica afirmación de la imposibilidad del cambio. Cuando éste se produce, parece advertir el poeta, no es más que mera apariencia ${ }^{35}$. En todo caso, es Ovidio el primer autor en el que es el propio Júpiter (en cuya persona ya la literatura poshesiódica progresivamente había hecho confluir todas las figuras arcaicas del destino) el que reconoce su subordinación a la fuerza inamovible del fatum. Los dos pasajes son pronunciados por el rey del Olimpo y, lo que es más importante tratándose de Ovidio, no hay intermediarios a la voz autorial ya que las palabras del padre de los dioses no se producen en ninguna ocasión en el nivel hipodiegético. En realidad, tal sistematicidad en la noción del fatum no tiene precedentes ni en la épica griega ni en la romana. Intratextualmente, el poder del amo de los cielos resulta ser incluso inferior al de Medea quien, recurriendo únicamente a su magia, fue capaz de de rejuvenecer a Esón (Met. VII 285-292). Baco, admirado por tal prodigio, acudirá a ella para devolver la juventud a sus nodrizas (VII 294-296).

El Júpiter de Ovidio, que no puede devolver la juventud a sus hijos Éaco, Minos y Radamantis, ni salvar de la muerte a César, está lejos del Zeus de Homero y del Júpiter de Virgilio. Soy consciente de que el estudio de las relaciones del padre de los dioses homérico y virgiliano con el destino ha hecho correr muchos ríos de tinta, por lo cual mi anterior afirmación pudiera resultar simplificadora. Obviamente, no es mi intención contribuir a la resolución de un aspecto de la teología homérica que considero, simplemente, inextricable. Pero es innegable que Zeus en la Ilíada se declara capaz de salvar a su hijo Sarpedón (XVI 434-438) y a su amado Héctor

\footnotetext{
${ }^{34}$ Sola insuperabile fatum, / nata, mouere paras? intres licet ipsa sororum / tecta trium: cernes illic molimine uasto / ex aere et solido rerum tabularia ferro, / quae neque concursum caeli neque fulminis iram / nec metuunt ullas tuta atque aeterna ruinas; / inuenies illic incisa adamante perenni / fata tui generis: legi ipse animoque notaui / et referam. (Met. XV 807815). Véanse también Met. I 256-258, V 532.

${ }^{35}$ Recuérdese Met. II 485 (pasaje ya mencionado en p. 13): mens antiqua tamen facta quoque mansit in ursa. Cf. también n. 21.
} 
(XXII 174-176). Como es sabido, tras escuchar las advertencias respectivamente de Hera y Atenea, no lo hace. No obstante, la ineludible realidad textual es que puede hacerlo. En lo que a Virgilio respecta, lo cierto es que «only a rash person would claim to 'understand' the relationship between Jupiter and Fate in the Aeneid» (Feeney 1991, p. 307), un poema en el que, inopinadamente y de forma súbita, Júpiter adquiere un cierto sabor ovidia$n^{36}$. El de Sulmona, al contrario, no deja lugar a dudas y hace gala de una claridad que emula la del Prometeo de Esquilo ${ }^{37}$. Ahora bien, está del todo punto ausente del interés de Ovidio sumarse a la dialéctica que el drama esquileo plantea entre la religiosidad arcaica y la religiosidad democrática. Sorprendentemente, en la teología ovidiana no hay lugar para las paradojas a las que el poeta era tan adepto.

Consciente de que pudiera parecer que incurro en contradicción, apelaré ahora a Séneca; pero no al Séneca teólogo sino al pensador político. En Sobre la clemencia es constante el énfasis del filósofo en que el princeps ha sido elegido para desempeñar en la tierra el papel de los dioses (Cl. I 1.2, 5.7, 19.8), cuya benevolencia ha de imitar ( $\mathrm{Cl}$. I 7.1-2). La potestas de Nerón, como la de Júpiter, es incontestable (Cl. I 1.2). Séneca, de hecho, en sus profilácticos consejos de cómo alcanzar la $\alpha \dot{\alpha} \alpha \theta \varepsilon 1 \alpha$ no parecía tener demasiados problemas en equiparar el sistema de gobierno divino al de una monarquía humana: in regno nati sumus: deo parere libertas est (Dial. VII 15.7). No obstante, toma las debidas precauciones en el sentido contrario. Así, se cuida de señalar los límites de esta divinización del poder absoluto del princeps humano. En primer lugar, la cólera de Nerón, al contrario que el fatum, ha de ser revocable (Cl. I 5.6, 20.3; Dial. III 6.3). En segundo lugar, el emperador no tiene poder sobre su propia vida: errat enim, si quis existimat tutum esse ibi regem, ubi nihil a rege tutum est ( $\mathrm{Cl}$. I 19.5). Y en tercer lugar, la condición del rector lleva implícita la subordinación. Esta supeditación, obviamente, guarda similitudes con la condición del Júpiter providencial que, aporéticamente,

${ }^{36}$ Cf. Aen. IX 94-97; X 8-9, 34-35, 113, 467-472. No obstante, estos pasajes virgilianos son intratextualmente problemáticos respecto a las sentencias del padre de los dioses en Aen. I 257, 260-262, y a las palabras de Venus en I 229-230 y de Juno en X 628-629, 632.

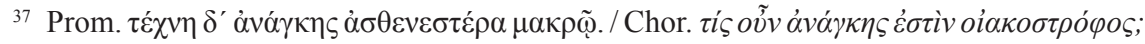

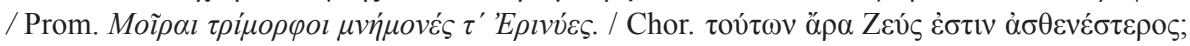

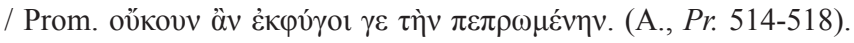


semper paret, semel iussit (Dial. I 5.8). Pero ahora la cuestión de los límites del poder de Nerón no se presta a formulaciones anfibológicas. Todo es ovidianamente mucho más sencillo. Su poder es, de forma inconcusa, limitado:

In hoc adsiduis bonitatis argumentis probauit non rem publicam suam esse, sed se rei publicae ( $C l$. I 19.8).

Caesari quoque ipsi, cui omnia licent, propter hoc ipsum multa non licent. ... Ex quo se Caesar orbi terrarum dedicauit, sibi eripuit, et siderum modo, quae inrequieta semper cursus suos explicant, numquam illi licet subsistere nec quicquam suum facere (Dial. XI 7.2).

En mi opinión, este princeps, divino pero mortal, tiene un exacto correlato en el Júpiter ovidiano y estaciano. Estoy lejos de poder demostrar que el rector Olympi o rector deum de Ovidio (Met. II 60, 848, IX 245, 499, XIII 599, XV 860), casi humano y, sin duda, trasunto del emperador Augusto ${ }^{38}$, ha servido de modelo al retrato que Séneca hace del ciuitatis rector (Dial. III 6.3). Lo que sí parece obvio es que Ovidio, con mucha más contundencia que ninguno de los poetas augusteos, expresa una ideología del principado que tiene clara continuidad en Séneca y en Lucano, pero también en Estacio. En este sentido, cabría preguntarse si la explícita presentación que tanto Ovidio como Estacio hacen del exiguo poder de Júpiter sobre el fatum en los pasajes analizados tiene algo que ver con la recurrente identificación que ambos poetas establecen entre las asambleas divinas y el Palatino a lo largo de sus composiciones ${ }^{39}$ y, más concretamente, entre Júpiter, Augusto y Domiciano ${ }^{40}$. Es decir, en

\footnotetext{
${ }^{38}$ El propio poeta lo explicita: Júpiter y Augusto son ambos «padres y caudillos» (Met. XV 860: pater est et rector uterque).

39 Por citar algún ejemplo, Ou., Met. I 172 (atria nobilium), 173 (deorum ... plebs), 174 (penates), 176 (dixisse Palatia); VI 73 (augusta grauitate), 74 (regalis imago); IX 245 (populi ...rectorque paterque), 419 (uario superi sermone fremebant), 427 (turbida seditio), 428 (si qua est reuerentia); Stat., Theb. I 197 (atria caeli), 203 (solio), 205-206 (turba uagorum / semideum).

${ }^{40}$ La bibliografía sobre esta última cuestión es muy abundante. Me limitaré a mencionar a Otis 1970 [or. 1966], p. 98; Ahl 1985, p. 69; Dominik 1994, pp. 79-97, 133-134, 148 y 161; Anderson 1997, p. 171; Rosati 2001, p. 53; Hill 2008, p. 141, y Romano 2009, pp. 246-250.
} 
el sentir de Ovidio y Estacio, el poder de los emperadores tiene que ser limitado pues incluso es limitado el poder de su alter ego divino. Es más, Estacio habría llegado incluso más lejos que el propio Ovidio. Aunque el sintagma rectorque paterque que el de Sulmona refiere a Júpiter y Augusto (Met. XV 860) «diventerà canonica per designare poi il potere imperiale» (Rosati 2001, p. 53), Estacio sólo se refiere a Júpiter como rector en una ocasión (Ach. II 53) y opta por escamotear a Domiciano el calificarlo abiertamente como tal ${ }^{41}$. No obstante, de forma reiterada aplica el apelativo rector al rey del infierno, Plutón ${ }^{42}$. Y en el infierno estaciano habitan las Euménides, pero sin duda también las Parcas ${ }^{43}$ que, según el conocimiento privilegiado de un Anfiarao que ha descendido vivo al Hades, obedecen las órdenes del nigri Iouis o del Tartarei rectoris (Theb. VIII 119: cum Parcae tua iussa trahant).

\section{BiBLIOGRAFÍA}

Adamini, G. 1981: «La raffigurazione del destino nella Tebaide di Stazio», Anazetesis 4-5, pp. 15-28.

Ahl, F. 1985: Metaformations: Soundplay and Wordplay in Ovid and Other Classical Poets, Ithaca.

Anderson, W. S. (ed.) 1997: Ovid's Metamorphoses: Books 1-5, Londres.

Aricò, G. 1963: «Ovidio in Stazio. Theb. V, 505 ss.», Aevum 37, pp. 120-123.

Bianchi, U. 1976: Prometeo, Orfeo, Adamo. Tematiche religiose sul destino, il male, la salvezza, Roma.

Billerbeck, M. 1986: «Stoizismus in der römischen Epik neronischer und flavischer Zeit», ANRW II 32.5, pp. 3116-3151.

Bobzien, S. 1998: Determinism and Freedom in Stoic Philosophy, Oxford.

Carrara, P. 1986: «Stazio e i primordia di Tebe: poetica e polemica nel prologo della Tebaide», Prometheus 12, pp. 146-158.

Colace, R. 1982: «Il nuovo Callimaco di Lille, Ovidio e Stazio», RFIC 110, pp. 140149.

${ }^{41}$ La formulación perifrásticamente equivalente a rector se encuentra en Theb. I 30: maneas hominum contentus habenis. En las Silvas, sólo en una ocasión Domiciano es rector y, en posición disjunta, pater (Silu. I 4.92, 95, respectivamente).

${ }^{42}$ Theb. IV 457, VIII 122, 193-194, XI 421; Ach. I 61. En una ocasión también lo refiere a Neptuno (Ach. I 78).

${ }_{43}$ Theb. VIII 12-13, 191. 
Criado, C. 1999a: «Antímaco de Colofón y la supercultura flavia», en Couceiro, J. L. et al. (eds.), Homenaxe ó profesor Camilo Flores, vol. II, Santiago de Compostela, pp. 234-243.

Criado, C. 1999b: «La praeteritio proemial de la Tebaida de Estacio. ¿Vocación cíclica o virgilianista?», Myrtia 14, pp. 101-107.

Criado, C. 2000: La teología de la Tebaida estaciana. El anti-virgilianismo de un clasicista, Hildesheim.

Criado, C. en prensa: «Theban Fratricides and Roman Civil Wars. The Destabilization of the Athenian Civic Myth».

Deipser, B. 1881: De P. Papinio Statio Vergilii et Ovidii Imitatore, Estrasburgo.

Delarue, F. 1988-1989: «Le palais du sommeil: d'Ovide à Stace», Lalies 10, pp. 405410.

Delarue, F. 1990: Stace, poète épique, thèse d'Etat, Université La Sorbonne-París.

Delarue, F. 2000: Stace, poète épique: originalité et cohérence, París.

Detienne, M. y Sissa, G. 1990: La vida cotidiana de los dioses griegos, Madrid.

Dominik, W. J. 1994: The Mythic Voice of Statius. Power and Politics in the Thebaid, Leiden.

Feeney, D. C. 1991: The Gods in Epic, Poets and Critics of the Classical Tradition, Oxford.

Galasso, L. 2009: «Giove e il fato nel IX libro delle Metamorfosi di Ovidio», MD 29, pp. 117-133.

Gildenhard, I. y Zissos, A. 2000: «Ovid's Narcissus (Met. 3.339-510): Echoes of Oedipus», AJPh 121.1, pp. 129-147.

Groß, A. 2003: Prophezeiungen und Prodigien in den Argonautica des Valerius Flaccus, Múnich.

Haase, W. 1973: «Providence and Fate in Stoicism and Pre-Neoplatonism: Calcidius as an Authority on Stoic Theodicy», Philosophia 3, pp. 262-306.

Hardie, Ph. 1988: «Lucretius and the Delusions of Narcissus», MD 20, pp. 71-89.

Hardie, Ph. 1990: «Ovid's Theban History: the first Anti-Aeneid?», CQ 40, pp. 224235.

Hardie, Ph. 1998: Virgil, Oxford.

Hardie, Ph. 2002: «Ovid and Early Imperial Literature», en Hardie, Ph. (ed.), The Cambridge Companion to Ovid, Cambridge, pp. 34-45.

Heinze, R. 1993 [1903']: Virgil's Epic Technique, Berkeley-Los Ángeles-Oxford.

Helm, R. 1892: De P. Papinii Statii Thebaide, Berlín.

Heuvel, H. 1932: Publii Papinii Statii Thebaidos liber primus, versione batava commentarioque exegetico instructus, Zutphen.

Hill, D. E. 2008: «Jupiter in Thebaid 1 again», en Smolenaars, J. J. L. et al. (eds.), The Poetry of Statius, Leiden-Boston, pp. 129-141 
Iglesias Montiel, R. 1991: «Estacio y sus modelos épicos», Actas del III Coloquio de Estudiantes de Filología Clásica. Poesía Épica Griega y Latina, 10, 11 y 12 de julio, Madrid, pp. 53-86.

Inwood, B. 2005: Reading Seneca. Stoic Philosophy at Rome, Oxford.

Kabsch, E. 1968: Funktion und Stellung des zwölften Buches der Thebais des P. Statius, Kiel.

Keith, A. 2002: «Ovidian Personae in Statius’ Thebaid», Arethusa 35.3, pp. 381402.

Kirk, G. S. 1992 [1974']: La naturaleza de los mitos griegos, Barcelona.

Kytzler, B. 1960: «Beobachtungen zum Prooemium der Thebais», Hermes 88.3, pp. 331-354.

Legras, L. 1905: Étude sur la Thébaïde de Stace, París.

Leibniz, W. G. 1900 [1710¹]: Theodicy. Essays on the Goodness of God, the Freedom of Man and the Origin of Evil, La Salle.

McNellis, Ch. 2007: Statius' Thebaid and the Poetics of Civil War, Cambridge.

Magris, A. 1985: L'idea di destino nel pensiero antico, Trieste.

Markus, D. D. 1997: The Politics of Entertainment: Tradition and Romanization in Statius' Thebaid, University of Michigan, Ann Arbor (diss.).

Markus, D. D. 2003: «The Politics of Entertainment: Tradition an Romanization in Statius' Thebaid», en Boyle, A. J. y Dominik, W. J. (eds.), Flavian Rome. Culture, Image, Text, Leiden-Boston, pp. 431-467.

Mozley, J. H. 1933: «Statius as an Imitator of Vergil and Ovid», $C W$ 27, pp. 33-38.

Mozley, J. H. 1969 [1928¹]: Statius, Londres.

Narducci, E. 1979: La provvidenza crudele. Lucano e la distruzione dei miti Augustei, Pisa.

Narducci, E. 2002: Lucano. Un'epica contro l'impero: interpretazione della Pharsalia, Roma.

Newlands, C. 2004: «Statius and Ovid: Transforming the Landscape», TAPhA 134, pp. 133-155.

Newman, J. K. 1975: «De Statio epico animadversiones», Latomus 34, pp. 80-89.

Otis, B. 1995 [1964']: Virgil. A Study in Civilized Poetry, Oklahoma.

Otis, B. 1970 [1966ㄹ]: Ovid as an Epic Poet, Londres.

Poebel, A. 1914: Historical and Grammatical Texts, Pensilvania.

Ramelli, I. 1999: «La concezione del divino in Stazio e la conversione del poeta secondo Dante», Gerion 17, pp. 417-432.

Río Torres-Murciano, A. 2006: El restablecimiento de la causalidad épica en el libro I de las Argonáuticas de Valerio Flaco, Santiago de Compostela (diss.).

Ripoll, F. 1998: La morale heroique dans les epopees latines d'epoque flavienne. tradition et innovation, Lovaina-París. 
Romano, S. 2009: El tópico grecolatino del concilio de los dioses, Hildesheim, Zúrich-Nueva York.

Rosati, G. 1999: «Form in Motion. Weaving the text in the Metamorphoses», en Hardie, Ph. et al. (eds.), Ovidian Transformations. Essays on Ovid's Metamorphoses and its Reception, Cambridge, pp. 240-253.

Rosati, G. 2001: «Mito e potere nell'epica di Ovidio», MD 46, pp. 39-61.

Rosati, G. 2002: «Muse and Power in the Poetry of Statius», en Spentzou, E. y Fowler, D. (eds.), Cultivating the Muse: Struggles for Power and Inspiration in Classical Literature, Oxford, pp. 229-252.

Rosati, G. 2008: «Statius, Domitian and Acknowledging Paternity», en Smolenaars, J. J. L., Van Dam, H.-J. y Nauta, R. R. (eds.), The Poetry of Statius, Leiden, pp. 175-194.

Schackleton Bailey, D. R. 2003: Statius. Thebaid, 2 vols., Cambridge, Mass.

Schetter, W. 1960: Untersuchungen zur epischen Kunst des Statius, Wiesbaden.

Schiesaro, A. 2002: «Ovid and the Professional Discourses of Scholarship, Religion, Retoric», en Hardie, Ph. (ed.), The Cambridge Companion to Ovid, Cambridge, pp. 62-75.

Schotes, H. A. 1969: Stoische Physik, Psychologie und Theologie bei Lucan, Bonn.

Schubert, W. 1984: Jupiter in den Epen der Flavierzeit, Frankfurt.

Taisne, A. M. 1994: L'esthétique de Stace, París.

Ten Kate, R. 1955: Quomodo heroes in Statii Thebaide describantur quaeritur, Groningen.

Thomas, E. 1959: «Some Reminiscences of Ovid in Latin Literature», Atti del Convegno Internazionale Ovidiano. Sulmona maggio 1958, vol. I, Roma, pp. 145171.

Thornton, A. 1976: The Living Universe. Gods and Men in Virgil's Aeneid, Lyon.

Thuile, W. 1980: Furiae in der nachklassischen Epik. Untersuchungen zu Valerius Flaccus' Argonautica, Papinius Statius' Thebais und Silius Italicus 'Punica, Innsbruck.

Venini, P. 1961a: «Studi sulla Tebaide di Stazio. L’imitazione», RIL 95, pp. 371400.

Venini, P. 1961b: «Studi sulla Tebaide di Stazio. La composizione», RIL 95, pp. 5588.

Venini, P. 1964: «Furor e psicologia nella Tebaide di Stazio», Athenaeum 42, pp. 201-213.

Vessey, D. W. T. C. 1973: Statius and the Thebaid, Cambridge.

Wheeler, S. M. 1999: A Discourse of Wonders: Audience and Performance in Ovid's Metamorphoses, Filadelfia. 
Wheeler, S. M. 2002: «Lucan's Reception of Ovid's Metamorphoses», Arethusa 35.3, pp. 361-380.

Zeitlin, F. 1986: «Thebes: Theater of Self and Society in Athenian Drama», en Euben, J. P. (ed.), Greek Tragedy and Political Theory, Berkeley, Los ÁngelesLondres, pp. 101-141.

Fecha de recepción de la primera versión del artículo: 22/07/2010 Fecha de aceptación: 27/12/2010

Fecha de recepción de la versión definitiva: 08/07/2011 